\title{
The role of T cell trafficking in CTLA- 4 blockade-induced gut immunopathology
}

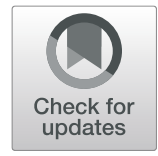

\author{
Shashuang Zhang ${ }^{1,2}$, Wenhua Liang ${ }^{1,2}$, Lingjie Luo ${ }^{1,2}$, Shan Sun ${ }^{1,2}$ and Feng Wang ${ }^{1,2^{*}}$
}

\begin{abstract}
Background: Immune checkpoint inhibitor (ICPI) can augment the anti-tumour response by blocking negative immunoregulators with monoclonal antibodies. The anti-cytotoxic T lymphocyte-associated antigen-4 (CTLA-4) antibody is the first ICPI which has shown remarkable benefits in the clinical treatment of cancers. However, the increased activity of the immune system also causes some side effects called immune-related adverse events (irAEs). Colitis is one of the most common irAEs related to anti-CTLA-4 immunotherapy.

Results: We identified that $C D 4^{+} T$ cells were the primary responders in CTLA-4 blockade and that the expansion of gut-homing $\mathrm{CD}^{+}{ }^{+} \mathrm{T}$ cells by anti-CTLA-4 therapy was independent of CD103. We used dextran sulfate sodium (DSS)-induced colitis mice as our model and tested the possibility of using a trafficking-blocking antibody to treat anti-CTLA-4 antibody-induced irAEs. We found that blocking $T$ cell homing increased colitis severity in the context of CTLA-4 blockade and that gut-trafficking blockade had different effects on different Th subsets and could facilitate the proliferation of Th17 cells in the lamina propria (LP).

Conclusions: Our data reveals the fundamental mechanism underlying trafficking-blocking antibody therapy for CTLA-4 blockade-induced colitis and provide a caution in regard to apply trafficking-blocking antibody treatment under CTLA-4 blockade condition.
\end{abstract}

Keywords: CTLA-4 blockade, Colitis, CD4 T cells, Trafficking-blocking antibody

\section{Background}

Cancer immunotherapy has become a powerful method to treat malignant tumours in addition to traditional methods such as surgery, radiotherapy and chemotherapy [1-3]. As one kind of immunotherapy, immune checkpoint inhibitor (ICPI) therapy has shown significant survival benefits in a wide range of cancers, including melanoma, lung cancer, kidney cancer and head and neck cancer $[1,4,5]$. ICPIs are a group of monoclonal antibodies that can reverse the immune tolerance mediated by cancer cells and generate a long-term anti-

\footnotetext{
* Correspondence: wangfeng16@sjtu.edu.cn

'Research Center of Translational Medicine, Shanghai Children's Hospital, Shanghai Jiao Tong University School of Medicine, Shanghai, China

${ }^{2}$ The Center for Microbiota and Immunological Diseases, Shanghai General Hospital, Shanghai Institute of Immunology, Department of Immunology and Microbiology, Shanghai Jiao Tong University School of Medicine, Shanghai, China
}

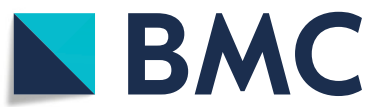

(0 The Author(s). 2020 Open Access This article is licensed under a Creative Commons Attribution 4.0 International License, which permits use, sharing, adaptation, distribution and reproduction in any medium or format, as long as you give appropriate credit to the original author(s) and the source, provide a link to the Creative Commons licence, and indicate if changes were made. The images or other third party material in this article are included in the article's Creative Commons licence, unless indicated otherwise in a credit line to the material. If material is not included in the article's Creative Commons licence and your intended use is not permitted by statutory regulation or exceeds the permitted use, you will need to obtain permission directly from the copyright holder. To view a copy of this licence, visit http://creativecommons.org/licenses/by/4.0/. The Creative Commons Public Domain Dedication waiver (http://creativecommons.org/publicdomain/zero/1.0/) applies to the data made available in this article, unless otherwise stated in a credit line to the data.

tumour immune response [6]. As the first ICPI, ipilimumab, which can block cytotoxic $\mathrm{T}$ lymphocyte-associated antigen-4 (CTLA-4), was approved by the US Food and Drug Administration (FDA) for the treatment of metastatic melanoma in 2011 [7, 8]. CTLA-4 is a negative regulator of co-stimulation that can control the initial activation and proliferation of $\mathrm{T}$ cells [9]. The blockade of CTLA-4 with anti-CTLA-4 antibodies can enhance the immune response to tumours $[10,11]$. However, the augmented immune response enabled by these agents also leads to a particular group of side effects called immune-related adverse events (irAEs) [12-16]. The distribution of grade 3-5 irAEs across all tumour types in the main clinical trial testing anti-CTLA-4 antibodies indicates that these side effects mainly occur in the gastrointestinal tract [17]. In an analysis of 193 fatal ICPI- 
related toxic events caused by anti-CTLA- 4 antibodies, 135 event $(\sim 70 \%)$ fatalities were related to colitis [18].

When somewhere in the body is attacked, the immune system will recruit various kinds of lymphocytes to the site to defend against pathogens. Hence, the trafficking and localization of lymphocytes is critical in tissue inflammation. The process of $\mathrm{T}$ cell homing to the gut requires $\beta 7$-containing integrins. $\beta 7$ is one of the integrin subunits; it noncovalently associates with the $\alpha 4$ subunit to become $\alpha 4 \beta 7$ integrin, which functions as a transmembrane cell adhesion receptor and is expressed on the surface of $\mathrm{T}$ cells. $\alpha 4 \beta 7$ integrin binds to its ligand mucosal addressin cell adhesion molecule-1 (MAdCAM-1), which is constitutively expressed on high endothelial venules, to mediate $\mathrm{T}$ cell extravasation from the blood to the gut mucosal tissues of the gut-associated lymphoid tissue (GALT), such as Peyer's patches (PPs), mesenteric lymph node (MLN) and lamina propria (LP) [19, 20]. Currently, trafficking-blocking antibodies have already become a novel class of immune intervention therapeutics in the clinic [21]. There are some trafficking-blocking antibodies that have been approved by the FDA or are in the process of being evaluated in clinical trials. For example, vedolizumab acts on gut-trophic $\alpha 4 \beta 7$ integrin and has been approved to treat inflammatory bowel disease (IBD) [22, 23]; etrolizumab, which is in the clinical trials for ulcerative colitis, can target and bind to the $\beta 7$ subunit [24]. Clinical case series suggest that vedolizumab is effective for treating steroidrefractory enterocolitis caused by ICPIs [25].

In this study, we chose the dextran sulfate sodium (DSS)-induced colitis mouse model, which is one of the most common models of chemically induced colitis in mice and is used to mimic human inflammatory bowel disease [26]. We combined the DSS model with the administration of an anti-CTLA-4 blocking antibody to investigate the mechanism by which CTLA-4 blockade influences intestinal inflammation [27]. In particular, we tested the possibility of treating irAEs induced by CTLA-4 blockade with a gut-homing traffickingblocking antibody by dissecting the molecular and cellular mechanisms underlying these processes.

\section{Results}

Gut-homing $\mathrm{CD}^{+}{ }^{+} \mathrm{T}$ cells are primary responders in CTLA4 blockade

To study the effect of CTLA-4 blockade on gut-homing $\mathrm{T}$ cells, we treated wild-type (WT) C57BL/6 mice with an anti-CTLA-4 antibody or isotype control antibody and examined $\mathrm{T}$ cells in the peripheral blood. Here, we used two indicators, CD44 and $\beta 7$; CD44 is a T cell activation marker, and $\beta 7$ indicates gut-homing $T$ cells. In the $\mathrm{CD} 4^{+}$subset, the percentage of activated gut-homing $\mathrm{CD}_{4}{ }^{+} \mathrm{T}$ cells was increased over 2 times after antiCTLA-4 antibody treatment compared with control treatment, while there was no significant change in blood $\mathrm{CD}^{+} \mathrm{T}$ cells (Fig. 1a). The other $\mathrm{T}$ cell activation marker, CD62L, also showed a similar pattern in the $\mathrm{CD}^{+}{ }^{+}$subset (Fig. 1b). We also detected the surfaceexpressed homing marker $\alpha 4$, and the number of $\alpha 4^{+} \mathrm{CD} 44^{+}$blood CD4 $\mathrm{T}$ cells also increased after CTLA-4 blockade, which was consistent with our $\beta 7$ expression data (Additional file 1: Figure S1). The staining result of isotype controls for both anti- $\beta 7$ and anti-CD44 antibodies in the Additional file 2: Figure S2. The gene expression profile from the Immunological Genome (ImmGen) database showed that the CTLA-4 expression level was significantly higher in the $\mathrm{CD}^{+}$subset (especially in Treg cells) than in the $\mathrm{CD}^{+}$subset (Additional file 3: Figure S3) [28]. Therefore, we can infer that gut-homing activated $\mathrm{CD} 4^{+} \mathrm{T}$ cells are the major responder population in anti-CTLA-4 blockade, at least in the initial stage.

\section{CTLA-4 blockade increases gut-homing CD4 T cell numbers independent of CD103}

From a previous study, we already know that $\mathrm{CD} 103^{+}$ dendritic cells (DCs) are the main regulators of intestinal $\mathrm{T}$ cell homing. When naïve $\mathrm{T}$ cells encounter relevant antigenic peptide-MHC complexes, they become activated, and $\mathrm{CD}_{103}{ }^{+} \mathrm{DCs}$ induce the upregulation of $\alpha 4 \beta 7$ and CCR9 expression on the $\mathrm{T}$ cell surface, which results in the interactions with the corresponding ligands that help the $\mathrm{T}$ cells migrate to sites of inflammation in the gut and execute their function [29]. To determine the underlying mechanism of gut-homing $\mathrm{T}$ cell expansion in the blood after CTLA-4 blockade, we first hypothesised that CTLA-4 blockade influences the classic gut-imprinting mechanism, which promotes the expression of $\alpha 4 \beta 7$. To test this possibility, we detected activated gut-homing $\mathrm{T}$ cells in CD103 knock-out (KO) mice. We found that the percentage of blood $\beta 7^{+} \mathrm{CD} 44^{+}$ cells decrease in the CD103 KO mice compared to their WT counterparts for both $\mathrm{CD}^{+}$and $\mathrm{CD} 8^{+} \mathrm{T}$ cell populations (Fig. 2a), which indicates that CD103 is responsible for $\beta 7$ expression and gut-homing imprinting in $\mathrm{T}$ cells. Surprisingly, when we treated mice with an antiCTLA-4 antibody, the fold increase in gut-homing CD $4^{+}$ $\mathrm{T}$ cells in CD103 KO mice was the same as that in WT mice (Fig. 2b). Therefore, we concluded that the increase in the number of gut-homing $\mathrm{CD} 4^{+} \mathrm{T}$ cells induced by anti-CTLA-4 therapy was the result of proliferation by pre-existing gut-homing $\mathrm{T}$ cells and did not require an additional CD103-dependent imprinting process.

\section{Gut tissue damage drives T cell homing under CTLA-4- blockade conditions}

Next, we used the DSS colitis model to test the effect of tissue damage on blood gut-homing $\mathrm{T}$ cells under 


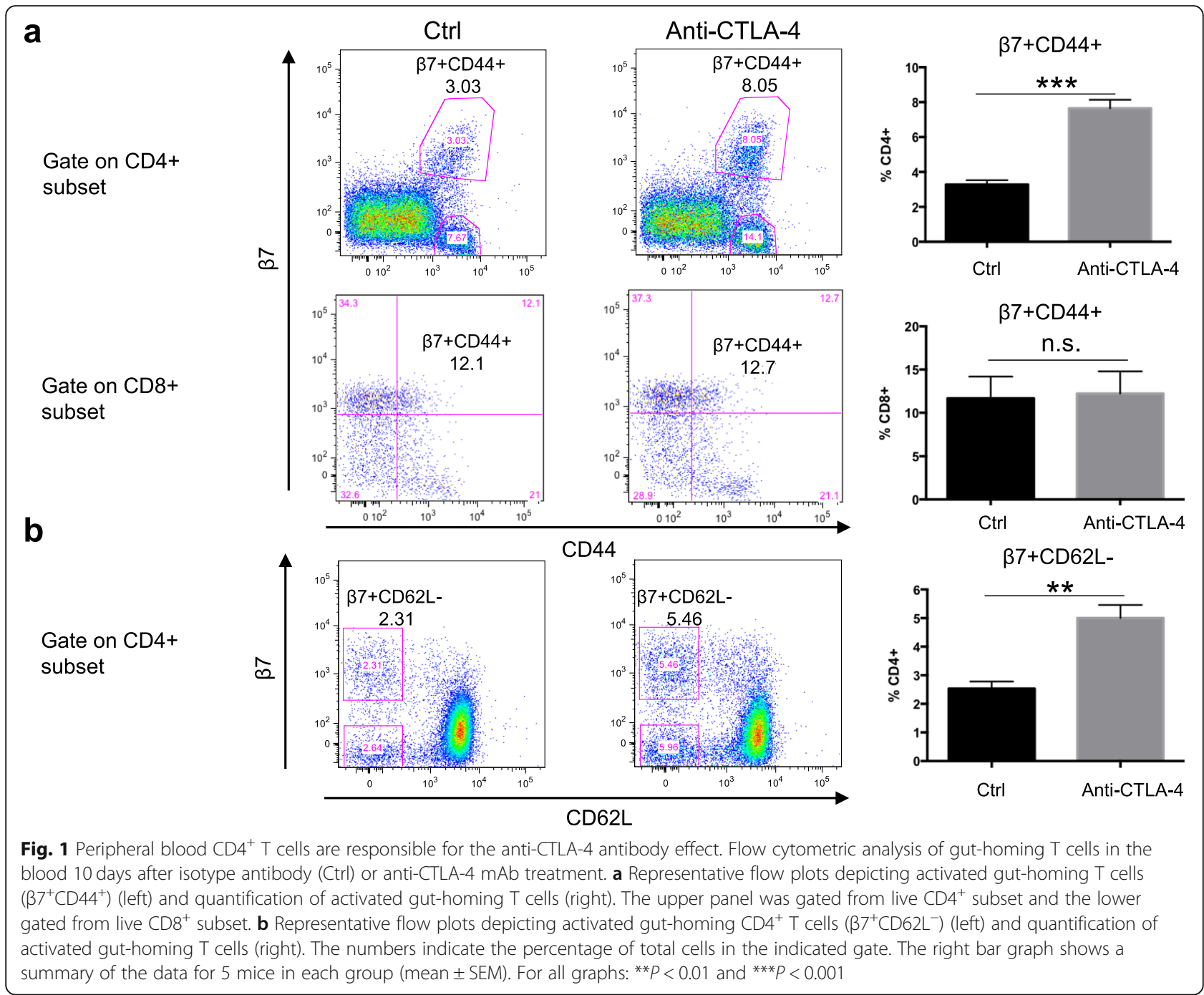

CTLA-4-blockade conditions. We divided WT mice into two groups: one group was injected with an anti-CTLA4 antibody every 3 days, and the other group was injected with an IgG isotype control. We then treated the mice with $1.5 \%$ DSS for 4 days beginning on day 15 , and on day 36 , we treated the mice again with $2.5 \%$ DSS (Fig. 3a). Consistent with our previous data [27], when we increased the concentration of DSS to $2.5 \%$, the group treated with CTLA-4 blockade exhibited a greater decline in weight than the isotype control group, which indicated that inflammation was more severe under CTLA-4-blockade conditions (Fig. 3b, upper panel). Histopathological scores of colon sections from antiCTLA-4 mAb-treated mice were also significantly worse than the group of mice that received isotype control antibodies (Fig. 3c). Serum levels of inflammatory cytokines, KC and IL6, were also increased in anti-CTLA-4 mAb-treated mice (Fig. 3d). At the same time, we analysed the dynamic change in blood gut-homing $\mathrm{CD} 4^{+} \mathrm{T}$ cells through monitoring the fold change in $37^{+} \mathrm{CD} 44^{+}$ subsets in the anti-CTLA-4 antibody-treated group versus the isotype control-treated group. We found that the fold change in gut-homing $\mathrm{T}$ cells in the blood increased gradually after anti-CTLA-4 antibody injection due to the proliferation of gut-homing $\mathrm{CD} 4^{+} \mathrm{T}$ cells driven by CTLA-4 blockade. When we treated mice with DSS to induce intestinal inflammation, the fold change declined correspondingly. The pattern changed along with the occurrences of DSS-induced intestinal damage during the whole process (Fig. 3b, lower panel). Moreover, we confirmed that the $\mathrm{CD} 4^{+} \mathrm{T}$ cell number in the blood of anti-CTLA-4 group mice at the end of the experiment was lower than that in the blood of control group mice (Fig. 3e), which correlated with severe $\mathrm{T}$ cell infiltration into the damaged intestinal tissue. These data demonstrated that anti-CTLA-4-blockade- and DSS-induced intestinal inflammation drove gut-homing $\mathrm{T}$ cell extravasation from the blood. 


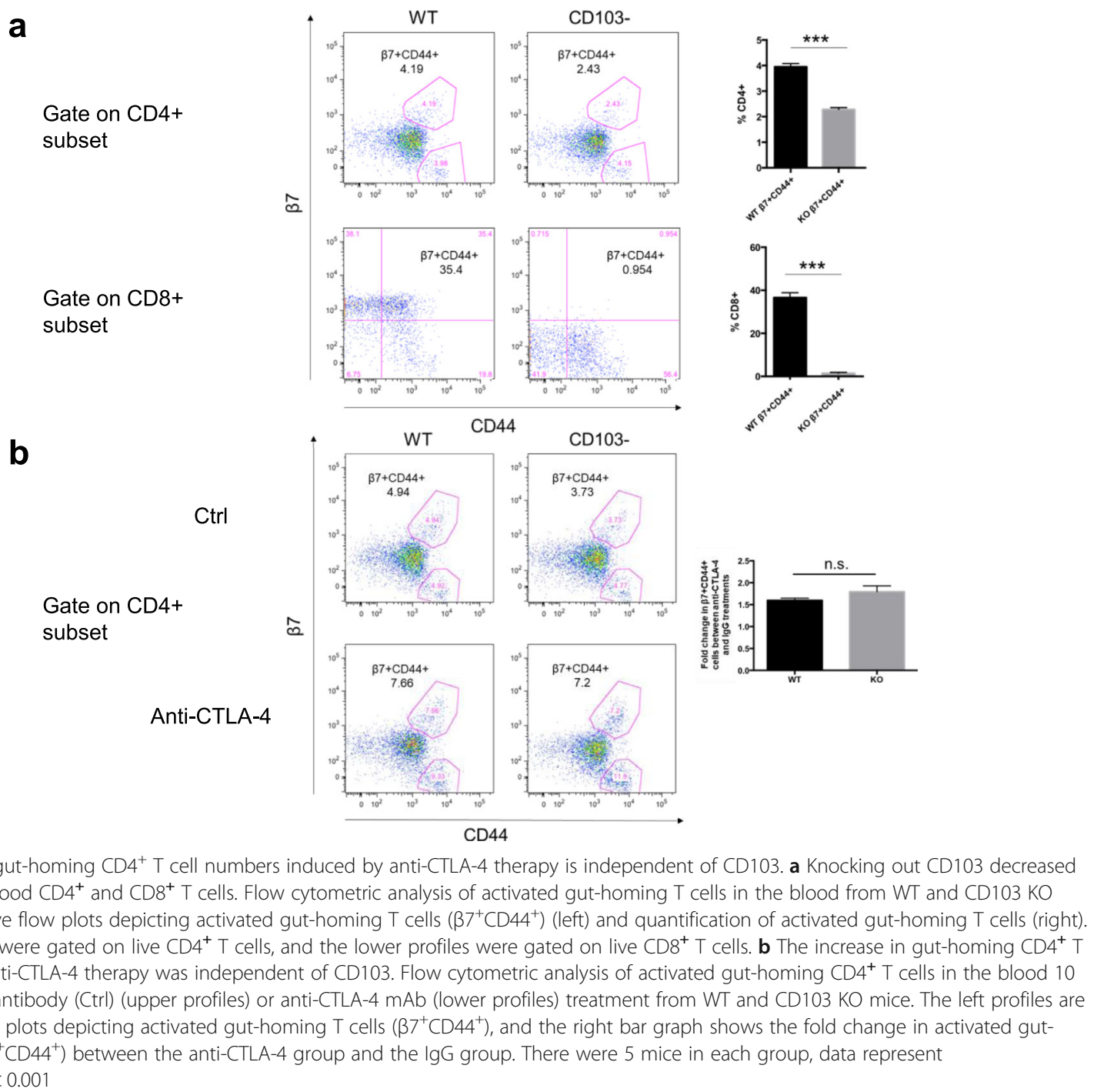

\section{Blocking T cell homing increases colitis severity under CTLA-4-blockade conditions}

Next, we wondered whether a $\mathrm{T}$ cell trafficking-blocking antibody could be used to treat colitis induced by DSS with or without CTLA-4 blockade. Here, we used the antibody clone FIB 504, which binds with $\beta 7$ integrin to block gut trafficking by leukocytes in mice [30]. We separated WT mice into 4 groups, injected antibodies every 3 days as indicated in the boxes and treated the mice with DSS at the beginning (Fig. 4a). When we treated the mice with the anti- $\beta 7$ antibody, gut homing by $\mathrm{CD} 4^{+}$ $\mathrm{T}$ cells was blocked efficiently regardless of whether CTLA-4 blockade was employed (Additional file 4: Figure S4). We found that the differences in weight and survival between the gut-trafficking blockade group and the control group were nonsignificant without CTLA-4 blockade, which suggested that gut-trafficking blockade does not affect DSS-induced colitis directly (Fig. 4b, c,
Additional file 5: Figure S5), consistent with a recent study showing that $\beta 7$ deficiency does not exacerbate intestinal inflammation unless in the setting of impaired Treg function [31]. However, when we treated the mice with the anti-CTLA-4 antibody, the trafficking blockade group developed more severe colitis than the control group, showing more dramatic weight loss and a lower survival rate (Fig. $4 \mathrm{~d}$, e).

\section{Gut-trafficking blockade has different effects on different Th subsets}

$\mathrm{CD} 4^{+} \mathrm{T}$ cells are classified into functionally distinct subsets, including the Th1, Th2, Th17 and Treg subsets. To determine whether a gut-trafficking blockade antibody has different effects on different $\mathrm{CD} 4^{+} \mathrm{T}$ cell subsets, we analysed the number of Treg, which is an immunosuppressive subset, and inflammatory Th17 cells in the LP after DSS treatment. Without CTLA-4 blockade, when 
a

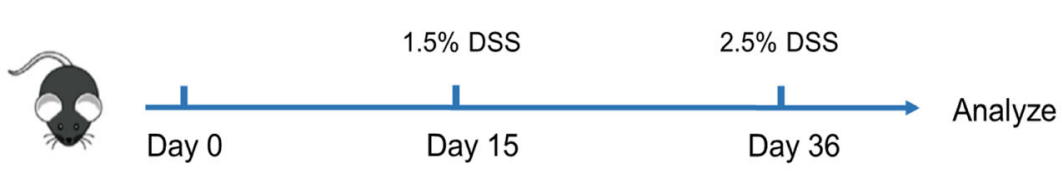

Anti-CTLA-4/lgG i.p.

(every 3 days)

b
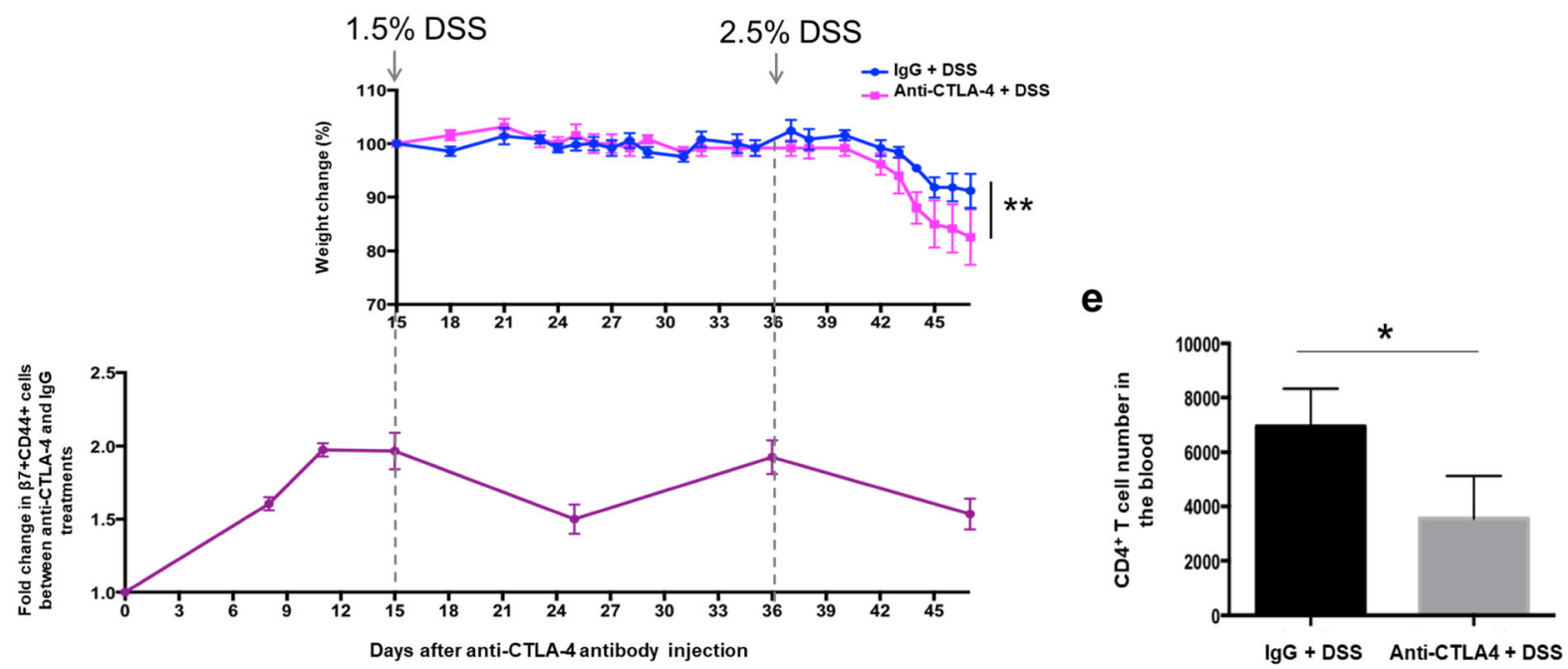

C

d
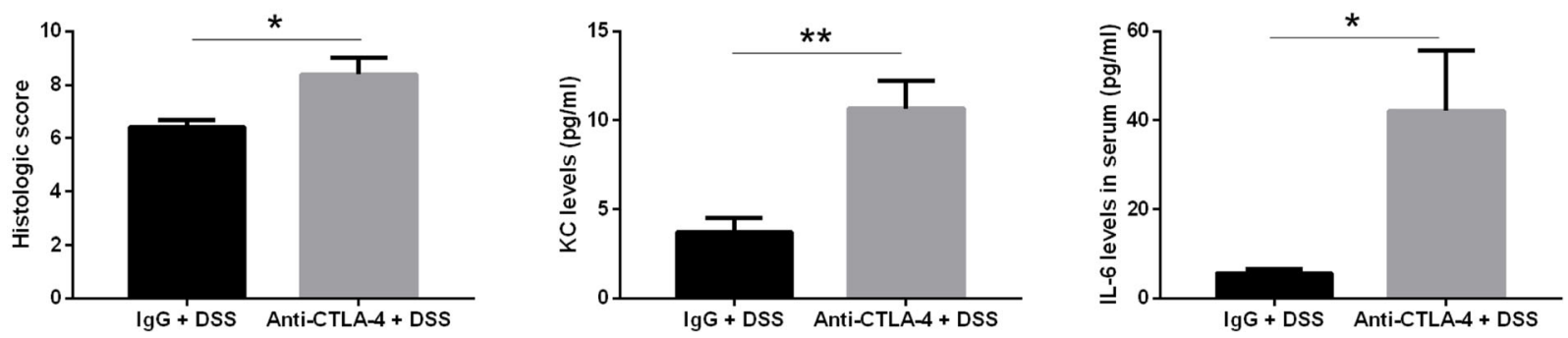

Fig. 3 Anti-CTLA-4 antibody- and DSS-induced inflammation drive gut-homing T cell extravasation from the blood. a The experimental design for the whole process. WT mice were treated with anti-CTLA-4 mAb or isotype control antibody every 3 days and given $1.5 \%$ DSS beginning on day 15 and 2.5\% DSS beginning on day 36, each time lasts 4 days and then changed back to water. $\mathbf{b}$ Percent of initial weight of mice receiving an IgG isotype control (Iso Ctrl) or anti-CTLA-4 mAb (upper profile). The dynamic change in blood $\beta 7^{+} C D 44^{+} C D 4^{+} T$ cells is shown as the fold change in $\beta 7^{+} C D 44^{+}$cells between the anti-CTLA-4 antibody-treated group and the lgG-treated group (lower profiles). There were 5 mice in each group. The data are shown as the mean and SEM determined by two-way ANOVA with Sidak's correction for multiple comparisons, $* * P<0.01$. $\mathbf{c}$ The histological score of mice receiving the IgG isotype control (Iso Ctrl) or the anti-CTLA-4 mAb. Colon samples were collected at day 47 . $\mathbf{d}$ Concentrations of KC and IL-6 in the serum of mice receiving the IgG isotype control (Iso Ctrl) or the anti-CTLA-4 mAb (day 47). e Summary of the blood $\mathrm{CD}^{+} \mathrm{T}$ cell numbers in the mice on day $47 . n=5$ per group, data represent mean \pm SEM. For all graphs: ${ }^{*} P<0.05$ and ${ }^{*} P<0.01$

we blocked $\mathrm{T}$ cell homing with the anti- $\beta 7$ antibody, the cell numbers in the LP were significantly decreased for both Treg and Th17 populations. This indicated that the trafficking-blocking antibody was generally effective in the context of DSS colitis (Fig. 5a). Overall colitis severity did not change due to the equal blockade of both inflammatory Th17 and immunomodulatory Treg populations (Fig. 4b). However, under the condition of CTLA-4 blockade, we found that compared to the isotype control, the anti- $\beta 7$ blocking antibody profoundly decreased the number of Tregs in the LP without affecting the number of Th17 cells (Fig. 5b). Our data suggest that the trafficking-blocking antibody has a biased effect on the numbers of Tregs and Th17 cells in the inflamed intestinal tissue under different CTLA-4-blockade conditions.

\section{CTLA-4 blockade facilitates the proliferation of Th17 cells in the LP}

Next, we investigated the reason why the treatment of trafficking blockade did not change the number of Th17 
a

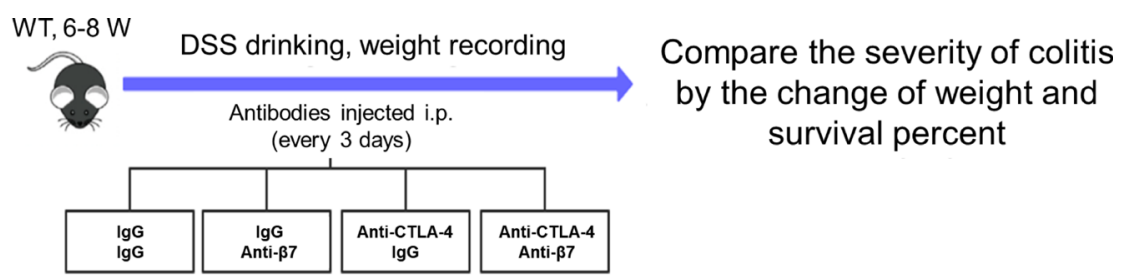

b

C

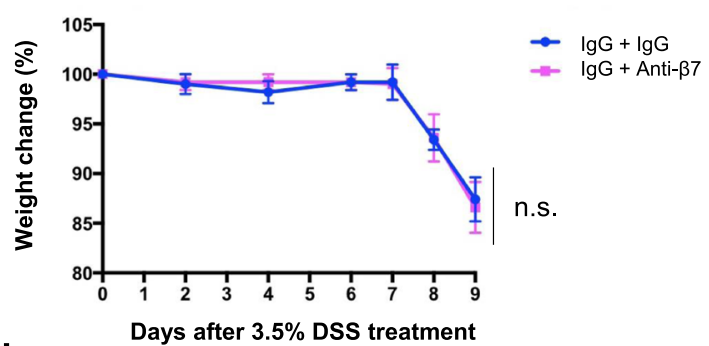

d
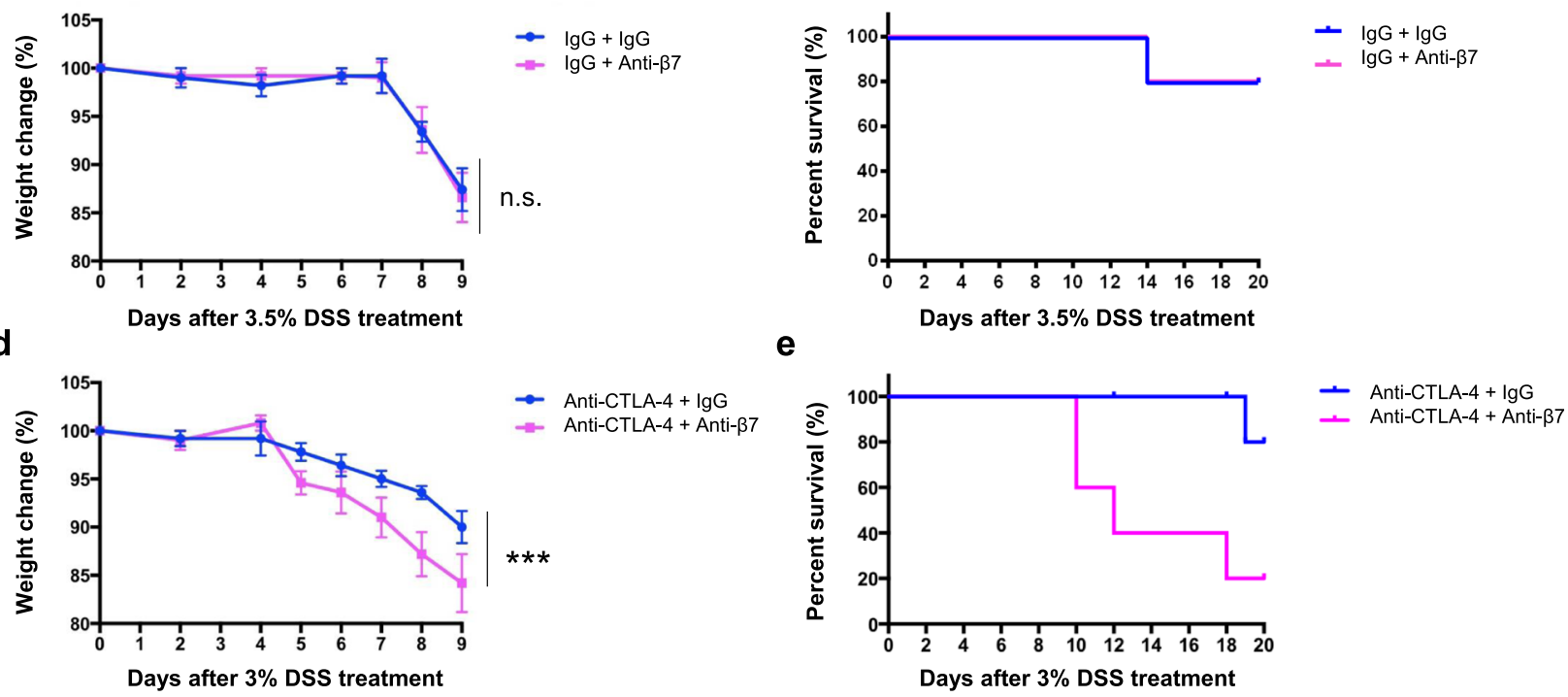

Fig. 4 Gut-trafficking blockade increases colitis severity under the condition of checkpoint blockade. a The experimental design for the whole process. b, c WT mice were given 3.5\% DSS for 7 days and treated without CTLA-4 blockade (IgG as the isotype control). Percent of the initial weight of mice receiving the lgG isotype control (Iso Ctrl) or anti- $\beta 7 \mathrm{mAb}(\mathbf{b})$. Survival of the mice receiving the lgG isotype control (Iso Ctrl) or anti- $\beta 7 \mathrm{mAb}$ (c). d, e WT mice were given 3\% DSS for 7 days and treated with CTLA-4 blockade. Percent of the initial weight of mice receiving the IgG isotype control (Iso Ctrl) or anti- $\beta 7 \mathrm{mAb}$ (d). Survival of the mice receiving the lgG isotype control (Iso Ctrl) or anti- $\beta 7 \mathrm{mAb}$ (e). There were five mice in each group. The data are shown as the mean and SEM determined by two-way ANOVA with Sidak's correction for multiple comparisons, ${ }^{* * *} P<0.001$. Survival was monitored for 20 days

cells under CTLA-4-blockade conditions. We treated mice with the anti-CTLA-4 antibody and detected the proliferation of $\mathrm{T}$ cell subsets in the peripheral blood and LP. Here, we analysed the percentages of Ki67 ${ }^{+} \mathrm{Th}$ subsets and found that the percentage of $\mathrm{Ki} 67^{+}$Tregs was substantially increased in the peripheral blood after CTLA-4 blockade, while the population of Ki67 ${ }^{+}$Th17 cells showed no significant change (Fig. 5c), suggesting that the blood could be the main source of LP Tregs through the $\beta 7$-mediated gut-homing pathway. Moreover, in the LP, CTLA-4 blockade increased the proliferation of Th17 cells without affecting the Ki67 ${ }^{+}$Treg population (Fig. $5 \mathrm{~d}$ ). These data indicated that the local proliferation of Th17 cells instead of trafficking from the blood might be the major contributor under CTLA-4blockade conditions, which explained why the number of Th17 cells did not change in the LP after anti- $\beta 7$ antibody treatment (Fig. 5b).

\section{Discussion}

In our present study, we identified that $\mathrm{CD}^{+} \mathrm{T}$ cells were the primary responders in CTLA-4 blockade and that the expansion of gut-homing $\mathrm{CD} 4^{+} \mathrm{T}$ cells induced by anti-CTLA-4 antibodies was independent of CD103. Then, we further investigated the effect of a $\mathrm{T}$ cell trafficking-blocking antibody on CTLA-4 blockaderelated irAEs. We used DSS-induced colitis mice as our model and chose an anti- $\beta 7$ antibody to block the gut trafficking of leukocytes in the mice. Blocking $\mathrm{T}$ cell homing increased colitis severity under CTLA-4blockade conditions, which contrasted with our expectation. Through further research, we found that guttrafficking blockade had different effects on different Th subsets and could facilitate the proliferation of Th17 cells in the LP.

In summary, activated $\mathrm{T}$ cells traffic to the site of inflammation in the LP in DSS-induced colitis (Fig. 6a); if 
a

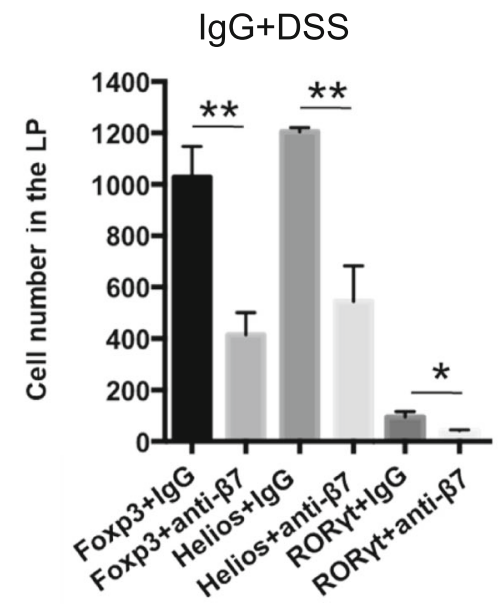

C $\quad \mathrm{Ki} 67^{+} \mathrm{Th}$ subsets in the PB on day 6

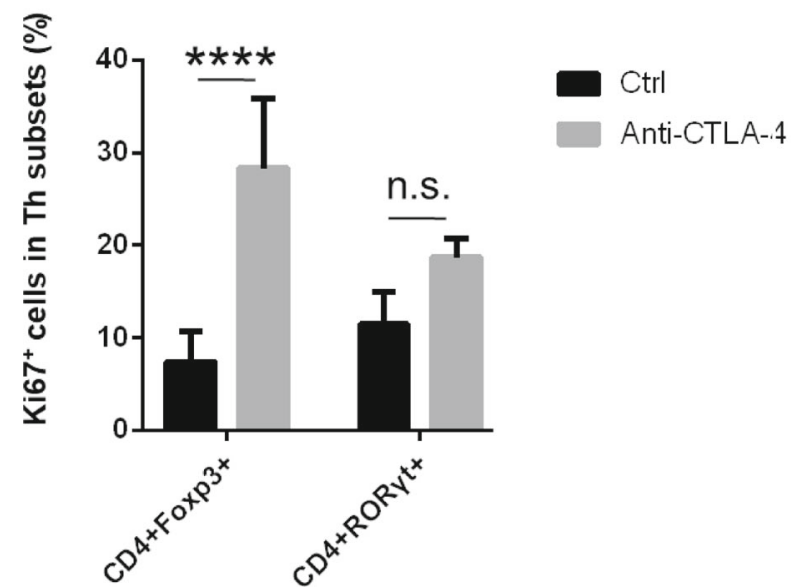

b
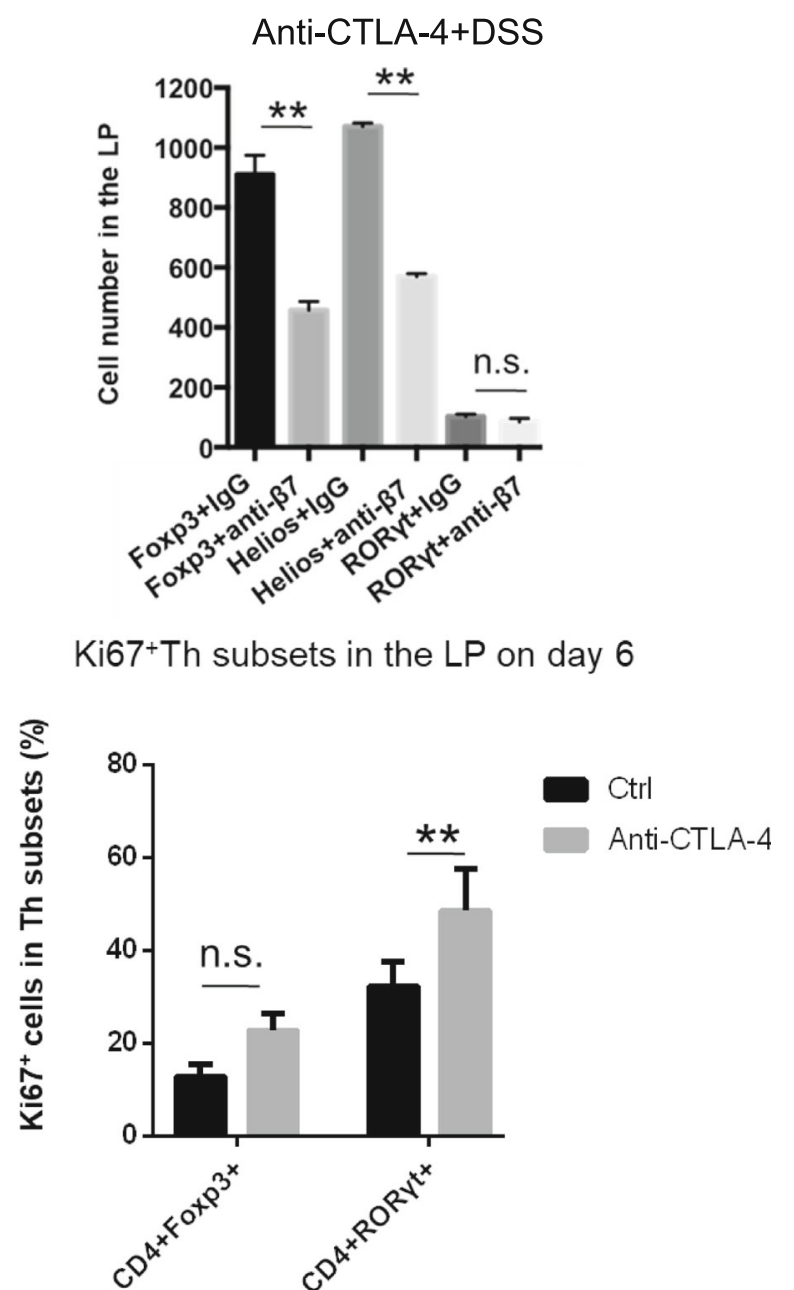

Fig. 5 Anti-CTLA-4 antibody treatment facilitates the proliferation of Th17 cells in the LP. $\mathbf{a}, \mathbf{b}$ The numbers of Tregs and Th17 cells in the LP on day 7 after treatment with the $\lg G$ antibody or anti- $\beta 7 \mathrm{mAb}, 2.5 \%$ DSS and without (a) or with (b) CTLA-4 blockade were determined. $\mathbf{c}$, $\mathbf{d}$ The percentages of Ki67 $7^{+}$Tregs and Th17 cells in the peripheral blood (c) and lamina propria (d) were determined 6 days after CTLA-4 blockade. There were 4-5 mice in each group. The data represent mean \pm SEM. For all graphs: ${ }^{*} P<0.05,{ }^{* *} P<0.01$ and ${ }^{* * *} P<0.0001$

we blocked the $\mathrm{T}$ cell homing process by injecting an anti- $\beta 7$ antibody, the Treg and Th17 cell numbers in the LP both declined (Fig. 6b). These data were consistent with a previous study showing that $\alpha 4 \beta 7$ antibody, vedolizumab, suppressed the homing of both Teff and Treg cells from IBD patients in a humanised mouse model [32]. However, when we treated mice with an antiCTLA-4 antibody, it promoted the proliferation of Tregs in the blood and the proliferation of Th17 cells in the LP (Fig. 6c). The majority of Tregs in the LP mainly accumulate through trafficking from the blood so if gut trafficking was blocked by the anti- $\beta 7$ antibody, the number of Tregs would decrease. Since compared to that of Tregs, the number of Th17 cells in the LP was small, it was easily compensated by enhanced local proliferation, which resulted in biased trafficking-blocking effects on the numbers of Tregs and Th17 cells under the CTLA-4-blockade condition (Fig. 6d).

There are two main reasons why we chose the DSSinduced colitis model instead of the cell transfer model in this study. The first reason is that DSS oral administration is a widely used animal model to induce colitis by damaging the gut epithelia. This model is better to mimic the clinical situation that patients suffer from gut inflammation by various intestinal damages. The second reason is that although DSS-induced intestinal damage can happen in CD4 T cell depletion/deficient condition [33], the severity of colitis was dramatically decreased in Rag-1 KO mice compared with that in WT mice [34]. These results, consistent with what we previously published work [27], demonstrated $\mathrm{T}$ lymphocyte-related intestinal inflammations contribute significantly to the severity of DSS-induced colitis. 
a

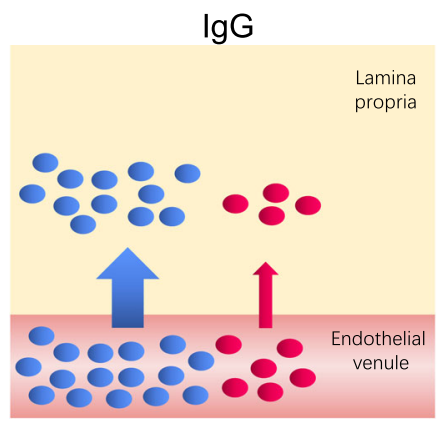

C

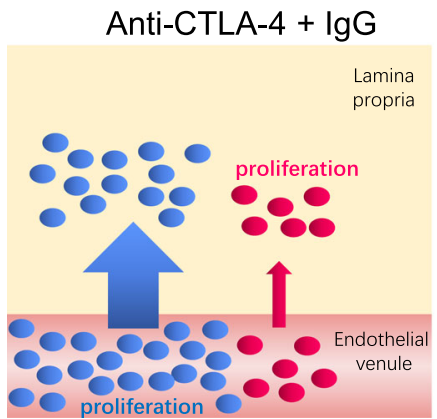

b

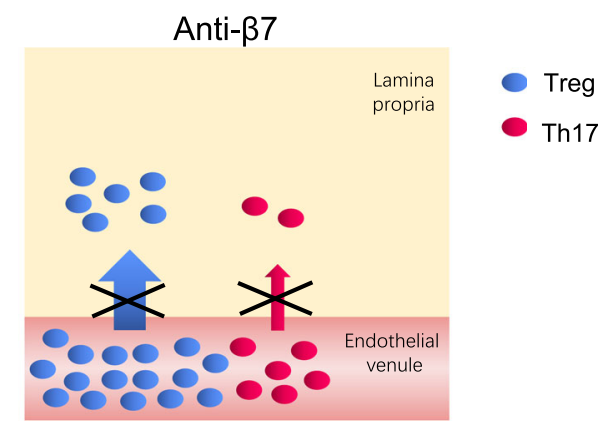

d

Anti-CTLA-4 + anti- $\beta 7$

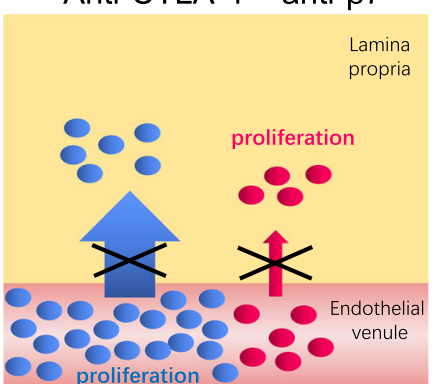

Fig. 6 The working model for the dynamic changes in different T cell subsets under CTLA-4 and $\beta 7$ blockade circumstances

Our work highlights a dynamic process of homing and proliferation for functional $\mathrm{T}$ cell subsets in the context of immune checkpoint blockade. At present, traffickingblocking antibodies are novel and potential drugs for IBD treatment with enhanced clinical effects and relatively few systemic adverse events [21]. Therefore, it is of great significance to illustrate the general clinical mechanism. A recent clinical report showed that seven patients who developed enterocolitis during ICPI therapy (with ipilimumab or nivolumab), six of whom had been treated with ipilimumab as a cancer therapy, were successfully treated with vedolizumab. During the treatment process, ICPI therapy was discontinued in all patients upon the development of grade 3 enterocolitis, and when response to treatment with corticosteroids indicated that these patients were either steroid refractory or steroid dependent, treatment with vedolizumab was started [25]. These clinical data combined with our results in a mouse model suggested that the timing between stopping ICPI therapy and beginning therapy with vedolizumab might be critical for efficacy. The other difference between our study and this clinical trial was that all the patients received corticosteroids before vedolizumab treatment, indicating that pre-treatment with an immunosuppressive drug might be required for the trafficking-blocking antibody to effectively reduce intestinal inflammation.

Besides, it is also worth noting that CTLA-4 may have different regulatory functions and requirements in mice and humans. Heterozygous Ctla4 knock-out mice were reported to be phenotypically normal, whereas heterozygous CTLA4 germline mutation will cause immune dysregulation disease in human $[35,36]$, which suggests that the regulatory network of CTLA-4 signalling pathway is more sensitive in human than mice.

\section{Conclusion}

In conclusion, our data reveals the fundamental mechanism of $\mathrm{T}$ cells underlying trafficking-blocking antibody therapy. Our funding provides a caution for applying a trafficking-blocking antibody to treat CTLA-4 blockadeinduced colitis. This work has significant implications for the clinical management of immune checkpoint therapy-induced adverse events.

\section{Methods}

\section{Mice}

C57BL/6 mice were purchased from Shanghai Ling Chang Biotech limited company, and CD103 KO mice were purchased from the Jackson Laboratory. For all experiments, 6- to 8-week-old female mice were used. Mice were maintained under SPF conditions in the Animal Science Centre at the Shanghai Jiao Tong University School of Medicine.

\section{Induction of DSS colitis and injection of antibody}

Mice received 2-4\% DSS (MP Biomedicals) in their drinking water for 6-7 days. Weight was recorded daily. 
Prepare the antibody (anti-CTLA-4 mAb, clone 9D9, BioXCell; anti- $\beta 7$, clone FIB504, BioXCell and isotype control, BioXCell) solution with PBS to $1 \mu \mathrm{g} / \mu \mathrm{l}$, intraperitoneal injection with $200 \mu \mathrm{g}$ per mouse every 3 days.

\section{Histological analysis}

Colon tissues were fixed with $4 \%$ paraformaldehyde and stained with haematoxylin and eosin. Each sample was given a score of $0-4$ based on the following criteria: (1) severity of inflammation, (2) percent of area affected by inflammation, (3) degree of hyperplasia, (4) percent of area affected by hyperplastic changes and (5) ulceration.

\section{Serum cytokine measurement}

Blood samples were collected at the last day (day 47) of the whole process. After clotting at least $30 \mathrm{~min}$ at room temperature, the serum was separated with centrifuge (10 min at 1200 relative centrifugal force). Luminex assay was performed following the product manual.

\section{LP isolation}

Sacrifice the mice, cut off the colons and remove the remaining fat tissue and the Peyer's patches first. Then cut longitudinally and wash in PBS. Transfer the colon into solution A (1 mM DTT, $30 \mathrm{mM}$ EDTA, $10 \mathrm{mM}$ HEPES) in order to remove epithelial cells. Transfer the colon into solution B (30 mM EDTA, $10 \mathrm{mM}$ HEPES) to remove the remaining DTT. Cut the colon into small sections and incubate in digest solution (collagenase VIII and DNase I: freshly add to 1640 Complete Medium, 1 : 600 ) and put it at $37{ }^{\circ} \mathrm{C}$ in a $5 \% \mathrm{CO}_{2}$ incubator for 55 min. Following the digestion step, pass the tissue through $100-\mu \mathrm{m}$ cell strainers, centrifuge and resuspend the cell pellet with $4 \mathrm{ml} 40 \%$ Percoll, mix thoroughly and carefully underlay $2.5 \mathrm{ml} 80 \%$ Percoll at the bottom of the $40 \%$ Percoll solution. Centrifuge $2500 \mathrm{rpm}, 25 \mathrm{~min}$ at RT (Acceleration 1, deceleration 1). Carefully harvest the mononuclear cells from the interphase of the $80 \%$ and 40\% Percoll gradient with Pasteur pipette, add cold PBS, mix thoroughly with Pasteur pipette and centrifuge 800 $g, 10 \mathrm{~min}$ at $4{ }^{\circ} \mathrm{C}$. Resuspend the pellets with PBS and pass through a $70-\mu \mathrm{m}$ filter. Centrifuge again, then resuspend the cells with FACS buffer (0.5\% BSA-PBS) and counting.

\section{Peripheral blood cell isolation}

Collect mice blood from the retro-orbital plexus, and use $2 \mathrm{mM}$ EDTA to prevent clotting. Filter through a $40-\mu \mathrm{m}$ filter, wash once with PBS and then prepare for the following staining step.

\section{Flow cytometry}

Cell surface antigen staining has used the following antibody conjugates in this study: anti-CD4 (clone RM4-5,
Biolegend), anti-CD8 (clone 53-6.7, Biolegend), antiCD44 (clone IM7, BD Biosciences), anti-62 L (clone MEL-14, Biolegend), anti- $\beta 7$ (clone FIB504, Biolegend), anti- $\alpha 4$ (clone R1-2, Biolegend), Rat IgG2b,k Iso control (clone eB149/10H5, eBioscience), Rat IgG2a, к Iso control (clone eBR2a, eBioscience) and LIVE/DEAD Aqua (Thermofisher), and was performed in the dark with antibody dilutions in FACS buffer (0.5\% BSA-PBS) for $30 \mathrm{~min}$ at $4{ }^{\circ} \mathrm{C}$. Cells were washed twice with FACS buffer, resuspended in FACS buffer and acquired or used for subsequent intracellular staining.

As for intracellular staining, after cell surface staining, cells were permeabilized by the fixation/permeabilization reagents (eBioscience) in the dark for $45 \mathrm{~min}$ at room temperature, then washed twice with permeabilization buffer and used for intracellular staining; the permeabilization process followed the specification.

Intracellular staining was performed in the dark at $4{ }^{\circ} \mathrm{C}$ with antibody dilutions in FACS buffer for $60 \mathrm{~min}$ and has used the following antibodies: anti-ROR $\gamma \mathrm{t}$ (clone AFKJS-9, invitrogen), anti-Foxp3 (clone FJK-16 s, eBioscience), anti-Helios (clone 22F6, eBioscience) and anti-Ki67 (clone B56, BD Biosciences). All flow cytometry analyses were performed on an LSRFortessa flow cytometer (BD Biosciences) and data were analysed with FlowJo X.

\section{Statistical analysis}

All values are shown as mean \pm SEM. Statistical significance was determined by Student's $t$ test. Statistical analysis was done with GraphPad Prism 7.

\section{Supplementary information}

Supplementary information accompanies this paper at https://doi.org/10. 1186/s12915-020-00765-9.

Additional file 1: Figure S1. $a 4^{+} C D 44^{+}$blood $C D 4^{+} T$ cell numbers increase after CTLA-4 blockade. Flow cytometric analysis of gut-homing $\mathrm{CD}^{+} \mathrm{T}$ cells in the blood 10 days after isotype antibody (Ctrl) or antiCTLA-4 antibody treatment.

Additional file 2: Figure S2. Isotype controls of anti- $\beta 7$ and anti-CD44 antibodies. Flow cytometric analysis of blood gut-homing $\mathrm{CD}^{+}$and $\mathrm{CD}^{+} \mathrm{T}$ cells collected from WT mice. Isotype control staining is shown as in the left panels. Isotype control for $\beta 7$ antibody is Rat IgG2a, $\mathrm{K}$ and isotype control for CD44 antibody is Rat lgG2b, $k$.

Additional file 3: Figure S3. $C D 4^{+}$subset exhibits a higher $C T L A-4$ expression level than the $\mathrm{CD}^{+}$subset. Gene expression data from the Immunological Genome for Ctla4 in reference population.

Additional file 4: Figure S4. Anti- $\beta 7$ antibody blocks gut-homing CD4 $T$ cells in the blood. Flow cytometric analysis of gut-homing $\mathrm{CD}^{+}{ }^{+} \mathrm{T}$ cells $\left(\beta 7^{+} \mathrm{CD} 44^{+}\right) 10$ days after lgG (isotype control) or anti-CTLA-4 antibody treatment with or without $\beta 7$ blockade (lgG as the isotype control).

Additional file 5: Figure S5. Gut-trafficking blockade does not affect $3 \%$ DSS-induced colitis directly. WT mice treated with the lgG isotype control (Iso Ctrl) or anti- $\beta 7$ mAb without CTLA-4 blockade (IgG as the isotype control), and given $3 \%$ DSS for 7 days. a Percent of the initial weight of mice receiving the lgG isotype control (Iso Ctrl) or anti- $\beta 7 \mathrm{mAb}$. b Survival of the mice receiving the lgG isotype control (Iso Ctrl) or anti- $\beta 7$ 
mAb. 5 mice in each group. The data are shown as the mean and SEM determined by two-way ANOVA with Sidak's correction for multiple comparisons. Survival was monitored for 20 days.

\section{Abbreviations}

CTLA-4: Cytotoxic T lymphocyte-associated antigen-4; DSS: Dextran sulfate sodium; FDA: Food and Drug Administration; GALT: Gut-associated lymphoid tissue; irAEs: Immune-related adverse events; ICPI: Immune checkpoint inhibitor; IBD: Inflammatory bowel disease; LP: Lamina propria; MAdCAM1: Mucosal addressin cell adhesion molecule-1; MLN: Mesenteric lymph node; PPs: Peyer's patches; WT: Wild-type

\section{Acknowledgements}

We sincerely thank Dr. Ruirong Yi for the assistances on experiments and the valuable suggestions about the paper writing.

\section{Authors' contributions}

FW conceived the project. SZ and FW designed and conducted the experiments. SZ, WL, LL and SS conducted the experiments. SZ and FW wrote the manuscript. The authors read and approved the final manuscript.

\section{Funding}

This study was supported by grants from the National Key Research and Development Program of China (SQ2018YFA090045-01), the National Natural Science Foundation of China (81771739), the Program for Professor of Special Appointments (Eastern Scholar) at Shanghai Institutions of Higher Learning, the Innovative Research Team of High-level Local Universities in Shanghai and the Technology Committee of Shanghai Municipality (18JC1414100).

\section{Availability of data and materials}

All data generated or analysed during this study are included in this published article and its supplementary information files.

\section{Ethics approval and consent to participate}

All animal experiments were approved by the Institutional Animal Care and Use Committee (IACUC) of Shanghai Jiao Tong University School of Medicine.

\section{Consent for publication}

Not applicable.

\section{Competing interests}

The authors declare that they have no competing interests.

Received: 19 August 2019 Accepted: 5 March 2020 Published online: 17 March 2020

\section{References}

1. Lipson EJ, Forde PM, Hammers HJ, Emens LA, Taube JM, Topalian SL. Antagonists of PD-1 and PD-L1 in cancer treatment. Semin Oncol. 2015; 42(4):587-600.

2. Dai H, Wang Y, Lu X, Han W. Chimeric antigen receptors modified T-cells for cancer therapy. J Natl Cancer Inst. 2016;108(7):djv439.

3. Hodi FS, O'Day SJ, Mcdermott DF, Weber RW, Sosman JA, Haanen JB, Rene G, Caroline R, Dirk S, Hassel JC. Improved survival with ipilimumab in patients with metastatic melanoma. N Engl J Med. 2010;363(8):711-23.

4. Ascierto PA, Daniele B, Hammers H, Hirsh V, Kim J, Licitra L, Nanda R, Pignata S. Perspectives in immunotherapy: meeting report from the "Immunotherapy Bridge", Napoli, November 30th 2016. J Transl Med. 2017; 15(1):205

5. Zimmer L, Eigentler TK, Kiecker F, Simon J, Utikal J, Mohr P, Berking C, Kämpgen E, Dippel E, Stadler R, et al. Open-label, multicenter, single-arm phase II DeCOG-study of ipilimumab in pretreated patients with different subtypes of metastatic melanoma. J Transl Med. 2015:13:351.

6. Samaan MA, Pavlidis P, Papa S, Powell N, Irving PM. Gastrointestinal toxicity of immune checkpoint inhibitors: from mechanisms to management. Nat Rev Gastroenterol Hepatol. 2018;15(4):222-34.
7. Azoury SDC, Straughan DM, Vivek S. Immune checkpoint inhibitors for cancer therapy: clinical efficacy and safety. Curr Cancer Drug Targets. 2015; 15(6):452-62.

8. Lawrence F, Small EJ. Anti-cytotoxic T-lymphocyte antigen-4 antibody: the first in an emerging class of immunomodulatory antibodies for cancer treatment. J Clin Oncol. 2008;26(32):5275-83.

9. Chambers CA, Krummel ME, Boitel B, Hurwitz A, Sullivan TJ, Fournier S, Cassell D, Brunner M, Allison JP. The role of CTLA-4 in the regulation and initiation of T-cell responses. Immunol Rev. 1996;153(1):27-46.

10. Buchbinder El, Desai A. CTLA-4 and PD-1 pathways: similarities, differences, and implications of their inhibition. Am J Clin Oncol. 2016:39(1):98-106.

11. Leach DR, Krummel MF, Allison JP. Enhancement of antitumor immunity by CTLA-4 blockade. Science. 1996:271(5256):1734-6.

12. Farolfi A, Ridolfi L, Guidoboni M, Nicoletti SV, Piciucchi S, Valmorri L, Costantini M, Scarpi E, Amadori D, Ridolfi R. Ipilimumab in advanced melanoma: reports of long-lasting responses. Melanoma Res. 2012;22(3): $263-70$

13. Robert C, Schachter J, Long GV, Arance A, Grob JJ, Mortier L, Daud A, Carlino MS, McNeil C, Lotem M, et al. Pembrolizumab versus ipilimumab in advanced melanoma. N Engl J Med. 2015;372(26):2521-32.

14. Rizvi NA, Julien M, David $P$, Stinchcombe TE, Dy GK, Antonia SJ, Leora $H$, Hervé L, Elisa M, Bertrand M. Activity and safety of nivolumab, an anti-PD-1 immune checkpoint inhibitor, for patients with advanced, refractory squamous non-small-cell lung cancer (CheckMate 063): a phase 2, single-arm trial. Lancet Oncol. 2015;16(3):257-65.

15. Topalian SL, Hodi FS, Brahmer JR, Gettinger SN, Smith DC, McDermott DF, Powderly JD, Carvajal RD, Sosman JA, Atkins MB, et al. Safety, activity, and immune correlates of anti-PD-1 antibody in cancer. N Engl J Med. 2012; 366(26):2443-54.

16. Weber JS, Kähler KC, Hauschild A. Management of immune-related adverse events and kinetics of response with ipilimumab. J Clin Oncol. 2012;30(21):2691-7.

17. Michot JM, Bigenwald C, Champiat S, Collins M, Carbonnel F, Postel-Vinay S, Berdelou A, Varga A, Bahleda R, Hollebecque A, et al. Immune-related adverse events with immune checkpoint blockade: a comprehensive review. Eur J Cancer. 2016;54:139-48.

18. Wang DY, Salem JE, Cohen JV, Chandra S, Menzer C, Ye F, Zhao S, Das S, Beckermann $\mathrm{KE}, \mathrm{Ha} \mathrm{L}$, et al. Fatal toxic effects associated with immune checkpoint inhibitors: a systematic review and meta-analysis. JAMA Oncol. 2018:4(12):1721-8.

19. Berlin C, Berg EL, Briskin MJ, Andrew DP, Kilshaw PJ, Holzmann B, Weissman IL, Hamann A, Butcher EC. a4 $\beta 7$ integrin mediates lymphocyte binding to the mucosal vascular addressin MAdCAM-1. Cell. 1993;74(1):185-95.

20. Wagner N, Löhler J, Kunkel EJ, Ley K, Leung E, Krissansen G, Rajewsky K, Müller W. Critical role for $\beta 7$ integrins in formation of the gut-associated lymphoid tissue. Nature. 1996:382(6589):366-70.

21. Park SC, Jeen YT. Anti-integrin therapy for inflammatory bowel disease. World J Gastroenterol. 2018:24(17):1868-80.

22. Feagan BG, Rutgeerts P, Sands BE, Hanauer S, Colombel J-F, Sandborn WJ Van Assche G, Axler J, Kim H-J, Danese S, et al. Vedolizumab as induction and maintenance therapy for ulcerative colitis. N Engl J Med. 2013;369(8): 699-710.

23. Sandborn WJ, Feagan BG, Rutgeerts P, Hanauer S, Colombel J-F, Sands BE, Lukas M, Fedorak RN, Lee $S$, Bressler B, et al. Vedolizumab as induction and maintenance therapy for Crohn's disease. N Engl J Med. 2013;369(8):711-21

24. Vermeire S, O'Byrne S, Keir M, Williams M, Lu TT, Mansfield JC, Lamb CA, Feagan BG, Panes J, Salas A, et al. Etrolizumab as induction therapy for ulcerative colitis: a randomised, controlled, phase 2 trial. Lancet. 2014; 384(9940):309-18.

25. Bergqvist V, Hertervig E, Gedeon P, Kopljar M, Griph H, Kinhult S, Carneiro A Marsal J. Vedolizumab treatment for immune checkpoint inhibitor-induced enterocolitis. Cancer Immunol Immunother. 2017:66(5):581-92.

26. Chassaing B, Aitken JD, Malleshappa M, Vijay-Kumar M. Dextran sulfate sodium (DSS)-induced colitis in mice; 2014.

27. Wang F, Yin $Q$, Chen L, Davis MM. Bifidobacterium can mitigate intestinal immunopathology in the context of CTLA-4 blockade. Proc Natl Acad Sci U S A. 2018;115(1):157-61.

28. Heng TSP, Painter MW, Elpek K, Lukacs-Kornek V Mauermann N, Turley SJ, Koller D, Kim FS, Wagers AJ, Asinovski N, et al. The Immunological Genome Project: networks of gene expression in immune cells. Nat Immunol. 2008; 9(10):1091-4 
29. Stock A, Napolitani G, Cerundolo V. Intestinal DC in migrational imprinting of immune cells. Immunol Cell Biol. 2013;91(3):240-9.

30. Andrew DP, Berlin C, Honda S, Yoshino T, Hamann A, Holzmann B, Kilshaw PJ, Butcher EC. Distinct but overlapping epitopes are involved in alpha 4 beta 7-mediated adhesion to vascular cell adhesion molecule-1, mucosal addressin-1, fibronectin, and lymphocyte aggregation. J Immunol 1994; 153(9):3847-61.

31. Sun H, Kuk W, Rivera-Nieves J, Lopez-Ramirez MA, Eckmann L, Ginsberg MH. $\beta 7$ integrin inhibition can increase intestinal inflammation by impairing homing of CD25(hi)FoxP3(+) regulatory T cells. Cell Mol Gastroenterol Hepatol. 2019;9(3):369-85.

32. Fischer A, Zundler S, Atreya R, Rath T, Voskens C, Hirschmann S, LópezPosadas R, Watson A, Becker C, Schuler G, et al. Differential effects of a4B7 and GPR15 on homing of effector and regulatory $T$ cells from patients with UC to the inflamed gut in vivo. Gut. 2016;65(10):1642-64.

33. Axelsson LG, Landström E, Goldschmidt TJ, Grönberg A, Bylund-Fellenius AC. Dextran sulfate sodium (DSS) induced experimental colitis in immunodeficient mice: effects in CD4(+) -cell depleted, athymic and NK-cell depleted SCID mice. Inflamm Res. 1996;45(4):181-91.

34. Kim TW, Seo JN, Suh YH, Park HJ, Oh Kl. Involvement of lymphocytes in dextran sulfate sodium-induced experimental colitis. World J Gastroenterol. 2006;12(2):302-5.

35. Kuehn HS, Ouyang W, Lo B, Deenick EK, Niemela JE, Avery DT, Schickel J-N, Tran DQ, Stoddard J, Zhang Y, et al. Immune dysregulation in human subjects with heterozygous germline mutations in CTLA4. Science. 2014; 345(6204):1623-7.

36. Schubert D, Bode C, Kenefeck R, Hou TZ, Wing JB, Kennedy A, Bulashevska A, Petersen B, Schaffer AA, Gruning B. Autosomal dominant immune dysregulation syndrome in humans with CTLA4 mutations. Nat Med. 2014; 20(12):1410-6.

\section{Publisher's Note}

Springer Nature remains neutral with regard to jurisdictional claims in published maps and institutional affiliations.

Ready to submit your research? Choose BMC and benefit from:

- fast, convenient online submission

- thorough peer review by experienced researchers in your field

- rapid publication on acceptance

- support for research data, including large and complex data types

- gold Open Access which fosters wider collaboration and increased citations

- maximum visibility for your research: over $100 \mathrm{M}$ website views per year

At $\mathrm{BMC}$, research is always in progress.

Learn more biomedcentral.com/submissions 